\title{
Design and Implementation of a Simulation- Based Learning System for International Trade
}
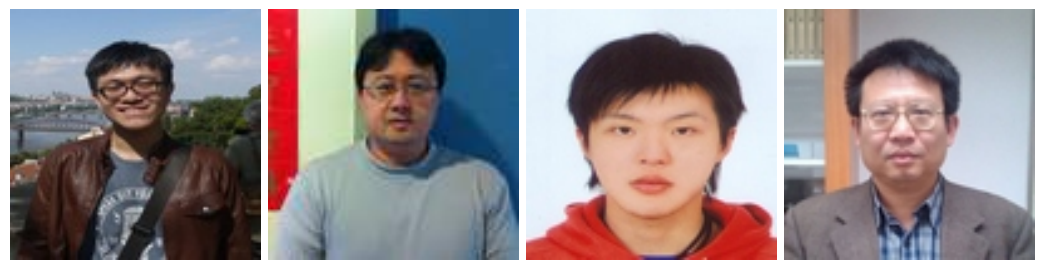

Guo-Heng Luo ${ }^{1}$, Eric Zhi-Feng Liu², Hung-Wei Kuo ${ }^{1}$, and Shyan-Ming Yuan ${ }^{1}$ ${ }^{1}$ National Chiao Tung University, Taiwan, ${ }^{2}$ National Central University, Taiwan

\section{Abstract}

In the traditional instructional method used in international trade, teachers provide knowledge to learners by lecturing using slides and setting assignments; however, these methods merely deliver international trade knowledge rather than facilitating student development of relevant skills. To solve these problems, we proposed a simulationbased learning system for international trade, combining international trade-process simulation and business letter writing. We investigated learner opinions toward the system and the quality of business letters by using quantitative and qualitative analyses. Regarding the results, learners perceived that the proposed system improved their knowledge of international trade and business English.

Keywords: Simulation-based learning; international trade; instructional technology; usability studies 


\section{Introduction}

The popularity of the Internet has increased the importance of Internet-based teaching and learning. Teachers have attempted to use learning management systems (LMS) and learning content management systems to enhance their teaching methods. Robinson and Schaible (1995) suggested collaborative teaching, in which teachers teach a subject or design learning activities and discuss and share their teaching experiences with other teachers. Teachers frequently use the Internet to instruct students (Curran, 2002). Because online classes are increasingly common, numerous researchers have attempted to develop innovative approaches that meet the needs of online learners and are not limited to face-to-face conferencing (Hyland \& Hyland, 2006; Miller, 2001; Peterson, 2001; Wible, Kuo, Chien, Liu, \&Tsao, 2001). DiNucci (1999) coined the term Web 2.0 to describe the features of information sharing, interoperability, user-centered design, and collaboration. In Web 2.0, information flow changes from unidirectional to bidirectional; recently, Web 2.0 has also been combined with e-learning, which is referred to as e-learning 2.0 (Downes, 2005).

In international trade, teachers traditionally provide knowledge to learners by using slides, setting assignments, or using other classroom-based teaching methods. For example, learners can be divided into groups, each of which is regarded as a trading company. The group members collaboratively discuss and prepare reports. To overcome physical access limitations, certain institutions have leveraged the Internet to facilitate teaching international trade, building e-learning systems that include teaching videos and slides. Learners can watch the teaching videos anywhere and at any time through the Internet. They can also download and study slides and submit homework through the system. This teaching method is similar to the traditional teaching method, allowing learners to conveniently study international trade by using the Internet. However, such methods enable only a partial understanding of the international trade process; thus, certain institutions have developed international trade classrooms or games to facilitate learning international trade (Houston \& Hoyt, 2001; Chiang, 2007). Although such methods are more attractive compared with traditional teaching methods, they present major disadvantages such as comprising an incomplete trade process and limited models.

To overcome the limitations of traditional teaching methods, international trade classrooms, and games, we proposed a simulation-based international trade learning system for both students and teachers, allowing students to practice writing English business letters and conducting international trade processes by using the Internet. Designing the virtual environment by using Web 2.0 technology ensures that the proposed system is suitable for face-to-face classes and after-school and distance learning. We designed several system functions that enable teachers to easily correct English business letters. We also surveyed user opinions toward the proposed system throughout two semesters, evaluating the quality of the generated letters. Few studies have presented the design and evaluation of e-learning systems that help students learn about international trade processes by using simulations. The proposed system assists 
students in writing business letters and conducting international trade through handson experiences. The findings should serve as a reference for both developers and teachers to improve system designs and the instructional methods used in international trade education.

\section{Literature Review}

\section{E-learning 2.0}

E-learning 1.0 differs from traditional learning methods; learners can learn anywhere and at any time by using an e-learning system (Ngai, Poon, \& Chan, 2007). Numerous studies have shown that e-learning yields greater positive effects compared with traditional face-to-face learning (Dutton, Dutton, \& Perry, 2002; Koory, 2003), facilitating increased interaction between the learner and computer. E-learning 1.0 supplements traditional learning materials, incorporating animations, computer games, and other computer-supported collaborative activities, positively motivating students and yielding a positive learning effect (Holzinger, 1997; Weiss, Knowiton, \& Morrison, 2002).

According to O'Reilly (2007), Web 2.0 is characterized by trusting users as codevelopers, harnessing collective intelligence, and leveraging the long tail through customer self-service. The slogan of the so-called read/write Web is "the user is the content." Alexander (2006) noted two features of Web 2.0: microcontent and social media. Cuene (2005) distinguished Web 1.0 and Web 2.0 from the user perspective: Web 1.0 comprises static web pages, whereas Web 2.0 refers to shared content among web users. Human-computer interaction changed between Web 1.0 and 2.0. In Web 1.0, users merely read web pages, but in Web 2.0, users actively contribute. Because of the increasing contributions of users, the level of collective intelligence and amount of reusable dynamic content has increased. Engaging with content establishes a sense of community, empowerment, and ownership among users. When appropriate systems and tools are available, amateurs can surpass professionals in knowledge; Wikipedia (http://wikipedia.org) is a widely recognized example of this phenomenon (Barsky, 2006; Barsky \& Purdon, 2006).

Web 2.0 encourages users to interact with other users, a feature that numerous theorists consider fundamental to e-learning (Kamel Boulos \& Wheeler, 2007). Interaction encourages deep and active learning engagement, builds learning communities, and enables learners to provide feedback to teachers (Fahy, 2003). Scholars have recently reported associations between teacher-learner interaction in online learning and increased levels of student motivation (Shea, Pickett, \& Peltz, 2003; Levy, 2007). 
Web 2.0 tools, such as wikis, blogs, and social networks, can be used in distance education or online courses to facilitate user interactions (Usluel \& Mazman, 2009; Smith, 2012); these tools facilitate collaborative working, information sharing, and effective communication. Applying emerging technologies alters the pedagogies involved in distance education. Anderson and Dron (2011) summarized three generations of pedagogies involved in distance education: cognitive-behaviorist, social constructivist, and connectivist. Web 2.0 technology belongs to connectivism, allowing students to explore, connect, create, and evaluate knowledge. Den Exter et al. (2012) studied the potential of using Web 2.0 technology, conducting two case studies that indicated Web 2.0 tools can be integrated to facilitate collaborative distance learning.

Downes (2005) discussed the perception of e-learning 2.0 in his article: "For all this technology, what is important to recognize is that the emergence of the Web 2.0 is not a technological revolution; it is a social revolution." E-learning 2.0 uses social network power to facilitate student learning. The critical aspect of a social network is a community of practice that is articulated and promoted by people. To emphasize the social power of elearning 2.0, Ebner (2007) proposed that e-learning $2.0=\mathrm{f}(\mathrm{e}-$ learning 1.0, Web 2.0, and the human factor). The formula shows that successful elearning 2.0 consists of users sharing content over the web (Web 2.0), the learning material is accessible through an LMS (e-learning 1.0), and Web 2.0 must be presented to the teacher and learners (the human factor).

\section{Common Errors in English usage}

We referred to numerous studies to design a colorful annotation module to classify common English usage errors, including the Online Annotator for English as a Foreign Language (EFL) Writing, developed by Yeh, Lo, and Huang (2006). This system replaces traditional paper-based error feedback and correction with interactive feedback and analysis. Using the system, learners write and teachers correct English compositions. The system is tailored to teach business English, and particularly writing English business letters. Certain differences exist between writing business letters and general English such as the architecture and rules. To classify business English and common usage errors, we referred to a computer-aided error analysis study (Dagneaux, Denness, \& Granger, 1998) that involved using standard text-retrieval software tools to analyze an error-tagged corpus; this method quickly yields the types of English errors and error counts. In the current study, we divided English writing errors into seven major types, which were subdivided into specific types.

Kubota (2001) studied learning a foreign language, focusing on Australian students learning the J apanese language. Although the current study did not explore learning English, this was a useful reference because it classified J apanese language errors; this facilitated generating classification rules.

To Chinese people, English is a foreign language. Potter (1992) authored a book elucidating common business English errors made by Chinese students in Hong Kong. 
The book included various examples that provided a solid foundation for establishing the error type categories used in the proposed system.

\section{Annotation and Learning}

Annotation refers to a comment added to the original text (Glover, $\mathrm{Xu}$, \& Hardaker, 2007). Online annotations allow students to learn based on conversations, whereas paper-based annotations are shared only through print technology (Wolfe, 2002). Regarding collaborative learning, Bargeron, Gupta, Sanocki, and Grudin suggested that annotations can provide contextual and personalized notes, enabling asynchronous collaboration among user groups (1999). Online annotations also enable users to add and share commentaries that are no longer limited to passively viewing content on the web. Ovsiannikov, Arbib, and Mcneill (1999) proposed that online annotations comprise four primary functions: remembering, thinking, clarifying, and sharing.

Several online annotation systems have been developed and applied to learning, including CoNote (Davis \& Huttenlocher, 1995), which enables a group of people to communicate by sharing annotations among sets of electronic documents. Yang (2006) proposed a personalized annotation management system to track seven types of annotations, including questions, explanations, commentaries, bookmarks, sketches, drawings, and links; this inspired researchers to explore various types of error annotations that could allow learners to quickly understand their errors. These studies

prove the usefulness of annotation systems in empirically evaluating real-life learning contexts.

Online annotations provide powerful functions, such as clarifying, sharing, and facilitating synchronous or asynchronous communications; thus, EFL teachers and learners experience an environment that engenders constructive error correction and feedback.

\section{Digital Simulation and Learning}

Various definitions have been proposed for digital simulation. After referencing several studies, Baek (2009) suggested, "A computer (digital) simulation can be defined as a program that models a system or a process." Simulations can be categorized into distinct types. In education, according to the teaching objective, Alessi and Trollip (2001) categorized simulations into those "about something" and those explaining "how to do something."

Simulations enable learners to experience specific situations, expanding beyond typical learning activities (Baek, 2009). Magee (2006) argued for employing simulations in education, indicating that they facilitated a risk-free environment, experimentation, problem-solving skills, assessments, and social interactions. Simulations are used to support learning in various approaches, such as constructivist learning, through 
learning-by-doing, improving higher order thinking by applying various teaching models, and supporting lifelonglearning as a tool (Baek, 2009).

Several simulation-based systems have been developed and applied to education. Regarding teaching "how to do something," Sawhney and Mund (1998) developed a simulation-based construction-management learning system, enabling students to learn how to manage construction projects. In this system, students use their knowledge and consider the given resources to plan the construction process before executing their simulation model. If the result is unsatisfactory, they can redesign their model and conduct iterative tests to determine an effective solution. This system provides a riskfree environment, reduces the costs deploying real construction plans, and provides hands-on experience. Regarding teaching "about something," Swaak and de J ong (2001) used a simulation-based discovery learning environment called CIRCUIT, simulating the behavior and voltage sources of electrical sources to explore the learning effect of this type of learning environment; the findings indicated that using the system increased the intuitive knowledge of students. Cho et al. (2012) developed a computer simulation-based smart learning system called EDISON for use in science and technology; the platform is used by 671 users at 14 colleges in South Korea for managing simulation tools, and provides a simulation environment, services, and computing resources. Students can use this system to easily perform various science experiments.

Few studies have investigated simulation-based learning systems for use in international trade education. Therefore, we designed, implemented, and conducted a preliminary evaluation of such a system. Leveraging simulation-based learning, online annotation, and e-learning 2.0 enables students to learn the international trade process and business letter writing.

\section{System Design}

\section{System Overview}

The proposed system enables students to learn international trade processes and business letter writing by acquiring hands-on experience in a simulated environment. Figure 1 illustrates the system components and component interactions of the proposed international trade practice learning system. 


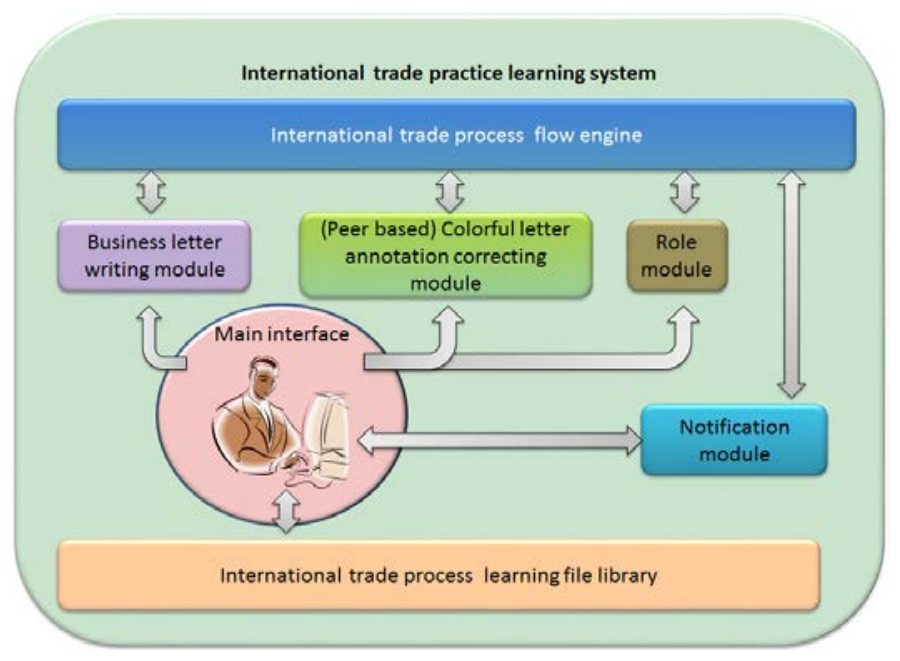

Figure 1. International trade practice learning system.

We designed the international trade process flow engine, notification module, and role module to provide a virtual environment for international trade. The primary interface provides users access to the business letter writing module, (peer based) colorful letterannotation correcting module, and international trade process learning file library. The process flow engine simulates the international trade process in 38 steps; system users encounter these steps in a way similar to the real world. The business letter writing module was designed to allow students to practice business letter writing. The letterannotation correcting module can be set to teacher or peer-based modes. The peerbased mode can be used to reduce teacher efforts regarding corrections, and the user conducting the correction can easily provide the error types and comments by using the module. The corrections are displayed as annotations in the letter, allowing students to recognize error types and providing directions for modification. A feedback mechanism helps students express their opinions or ask questions regarding corrections. After students receive corrections, they can ask the teacher (or peer corrector) questions or discuss and clarify the errors with their teammates. When students do not know what to do or how to begin writing, they can access the international trade process learning file library to obtain sample letters and knowledge regarding international trade.

\section{Virtual International Trade Environment}

Figure 2 shows the virtual international trade environment. The general administration department comprises teachers and system administrators. These parties can manage system settings, allowing peer-based correction or changing student roles. In the proposed system, we designed various departments similar to those in the real world such as trade companies, banks, and manufacturers. 


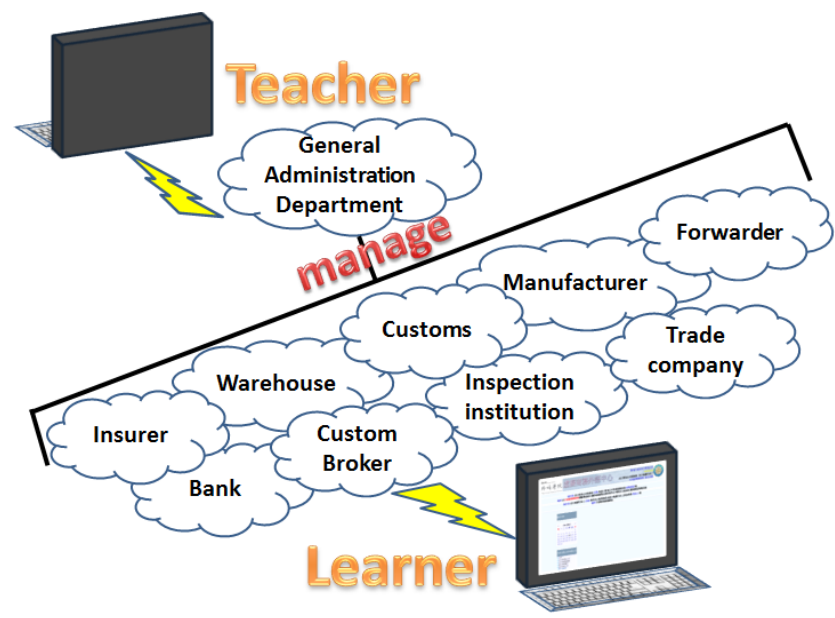

Figure 2. Virtual international trade environment.

\section{Business Letter Writing}

Writing business letters (or commercial mail) plays a critical role in the real-world international trade process. Learners must understand how to write business letters, using formal and correct English. The proposed system provides a platform for learners to write business letters and discuss their work with teachers or other learners.

Figure 3 shows the flow process for writing and correcting business letters. A learner first writes and submits a letter, and a teacher or student subsequently corrects the letter. All learners on a team can read these corrections, regardless of whether they are the author. After reading the correction comments, the team members discuss the letter and raise questions, which teachers or peer correctors answer. A team of learners can discuss the comments and content of the letter until they obtain the desired answer; thus, the author can rewrite the letter after learning how to improve it. 


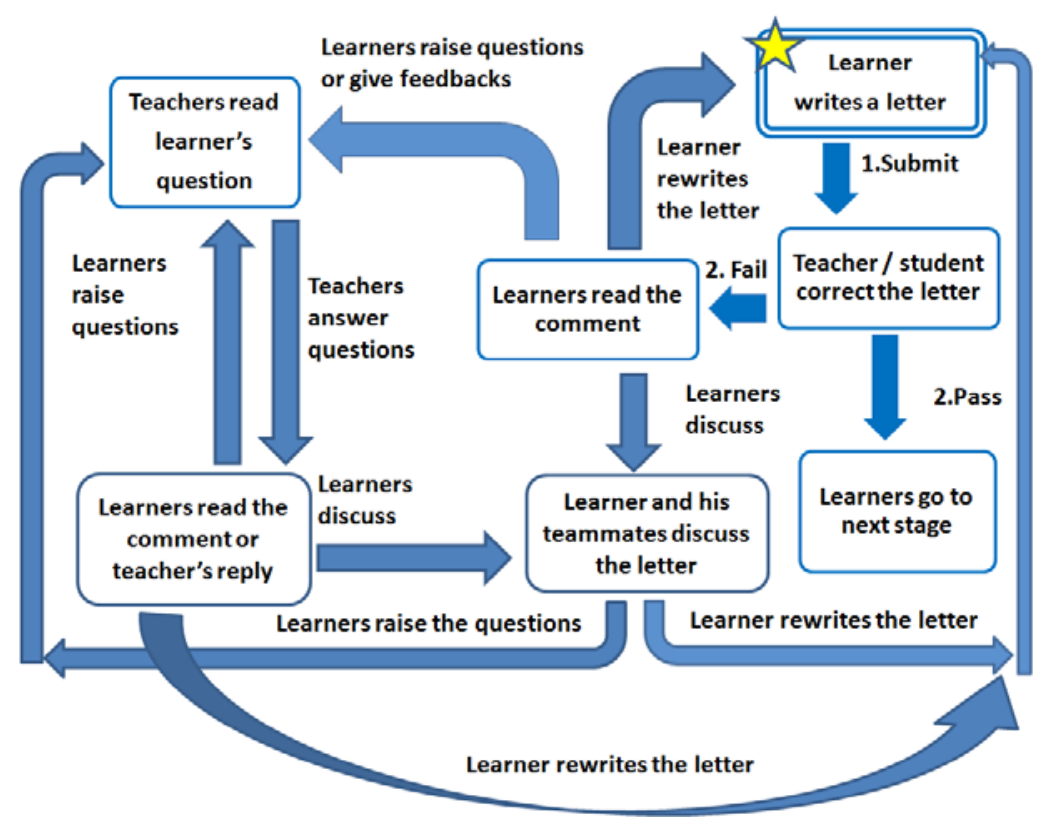

Figure 3. The flow of business letter writing.

\section{System Evaluation}

\section{Overview}

We investigated system usability and student opinions toward the proposed system throughout two semesters (summer 2011 and spring 2012). The course content was identical in each semester. Because students were allowed to take the course several times, certain students took both the first and second semester courses. No peer-based correction or role-changing mechanisms were involved in the first semester course; we added these mechanisms and several other system improvements after the first semester when we collected and analyzed student opinions toward the system. Following the second semester, we collected both learner and teacher opinions to determine the system improvement status.

\section{Sample}

The volunteer participants comprised 102 learners, of which 85 were undergraduate students and 17 were graduate students. The learners completed an online questionnaire; at the end of each semester, we received 49 and 24 valid questionnaires. We interviewed nine teachers in the language department, who also completed the questionnaire. 


\section{Procedure}

During each semester, the College of Foreign Languages and Literature of Providence University ran an international trade seminar course. The course objective was to instruct students regarding international trade and business-letter writing. Prior to the class, we used two class periods to introduce the proposed system. After the system introduction, the students attended normal classes, using the system to practice the international trade process after class. Students were allowed to take this course more than once. Before the end of each semester, the students completed the questionnaire. At the end of the second semester, the researchers interviewed nine teachers in the language department, who provided their opinions of the proposed system. Each teacher was introduced to the system and operated it for several minutes. At the end of the interview, each teacher completed a questionnaire.

\section{Materials}

The questionnaire used to evaluate the proposed system comprised two sections. First, we adopted the widely applied system usability scale (SUS) to evaluate system usability (Brooke, 1986). The questionnaire comprised 10 questions, and each item was scored from 1 (strongly disagree) to 5 (strongly agree). The total score for the odd numbered questions was the original score minus one, and 5 minus the original score for the even numbered questions. The SUS score was the sum of the total scores multiplied by 2.5, and the scores ranged from 0 to 100. A high total item score indicated that the proposed system performed effectively regarding that item.

In the second section of the questionnaire, three open-ended questions were used to investigate opinions toward the system. The question content included "What do you think about the International Trade Practice Learning System?" "Could any function of the International Trade Practice Learning System be improved?" and "What type of function or tool should be added to the International Trade Practice Learning System?"

\section{SUS Results Obtained from Students After the First Semester}

Table 1 presents the SUS questionnaire results, indicating that the average SUS score was 58.10. According to Bangor et al. (2009), a value greater than 55 scores between OK and good, implying that the proposed system should be scrutinized and improved. 
Table 1

SUS Results (First Investigation of Learner Side)

\section{System Usability Scale}

1. I think that I would like to use this system frequently.

2. I found the system unnecessarily complex.

3. I thought the system was easy to use

4. I think that I would need the support of a technical person to be able to use this system

5. I found the various functions in this system were well integrated.

6. I thought there was too much inconsistency in this system

7. I would imagine that most people would learn to use this system very quickly.

8. I found the system very cumbersome to use.

9. I felt very confident using the system.

10. I needed to learn a lot of things before I could get going with this system.

SUS score

\section{Contribution
mean}

$2.75 \quad 0.46$

$2.12 \quad 0.83$

$2.62 \quad 0.74$

$1.00 \quad 0.76$

$2.88 \quad 0.64$

$2.37 \quad 0.52$

$3.00 \quad 0.53$

$2.75 \quad 0.46$

$2.75 \quad 0.46$

$1.00 \quad 0.53$

58.10

All items yield standard deviations less than one, indicating that the student opinions were similar.

Item 7 yielded the highest mean score (3 points); the lowest scored items, Items 4 (1 point) and 10 (1 point), indicate that users believe the system can be easily learned and used, but the process may require technical support. The Item 10 score shows that using the proposed system requires considerable prior knowledge because the system is integrated with the international trade process. The demographic information indicated that numerous participants majored in the English language, law, and computer science. Few learners were international trade majors.

Although Item 5 (2.88) attained the second highest mean score, indicating that the functions of the proposed system were well integrated, the Item 2 score implied that the system is unnecessarily complex and should be simplified. 


\section{Open-Ended Question Results from the First Semester Students}

We used grounded theory to analyze the collected data. Based on keyword practice, the students indicated that knowledge learned from textbooks can be applied in the simulated environment. Apparently, international trade knowledge was recalled and used during the simulation. Students also indicated that the proposed simulation environment facilitated practicing business letter writing; thus, it enables practicing international trade skills. Using keywords such as complex, simplify, process, and easyto-use indicated that when learners become familiar with the system, it is easy to use; however, it remained unnecessarily complex. This is consistent with the results of the SUS. Numerous learners believed the proposed system process was complex and should be simplified. Based on the keyword instructions, learners believed the system instructions should be improved to help learners rapidly familiarize themselves with the system. Analyzing keywords, such as appealing and user-friendly, indicated that the

user interface should be enhanced and replaced with attractive icons. Finally, regarding additional functions, the learners sought communication functions such as chatting and video conferencing.

\section{SUS Results from the Second Semester Students}

Before the second semester, we considered the suggestions collected from the first semester students. We simplified the system flow, added a peer-based correction mechanism, a role-changing mechanism, and new detailed instructions. We also adjusted the system interface and functions. 
Table 2

SUS Results (Second Investigation of Learner Side)

$$
\text { System Usability Scale }
$$

1. I think that I would like to use this system frequently.

2. I found the system unnecessarily complex.

3. I thought the system was easy to use

4. I think that I would need the support of a technical person to be able to use this system

5. I found the various functions in this system were well integrated.

6. I thought there was too much inconsistency in this system

7. I would imagine that most people would learn to use this system very quickly.

8. I found the system very cumbersome to use.

9. I felt very confident using the system.

10. I needed to learn a lot of things before I could get going with this system.

SUS score

\section{Contribution
mean}

$2.75 \quad 0.46$

$2.62 \quad 1.06$

$2.88 \quad 0.99$

$2.25 \quad 1.16$

$3.00 \quad 0.53$

$2.37 \quad 0.74$

$3.13 \quad 0.35$

$2.62 \quad 0.52$

$2.75 \quad 0.46$

$2.00 \quad 1.41$

65.93

Table 2 presents a summary of the SUS results. The total SUS score increased to 65.93 in the second semester. According to Bangor et al. (2009), values greater than 65 score between OK and good, indicating that the proposed system should be further scrutinized and enhanced. Although the current version was superior to the previous version of the system, several problems require attention.

Similar to the first semester results, Items 7, 5, and 3 yielded the highest scores. The mean contributions of most items increased, particularly those of Items 4 (1.25 points) and 10 (1 point); thus, the proposed system improved in most dimensions. Moreover, the standard deviations of most items increased, particularly those of Items $10(0.88)$ and 4 (0.4), indicating slightly different student opinions toward the system.

In addition, both the contribution means and standard deviations of Items 4 and 10 increased; thus, compared with the first semester, more users in the second semester indicated that they did not require technical support to use the system. The item, "I need to learn several things before I can use this system" also improved. This result could be because of the detailed instructions, simplified process, and interface adjustments. However, detailed instructions may only help certain students solve problems because they are incomplete or certain users do not read these instructions when using the system. Although the system was improved, the level of required prior knowledge regarding international trade remained the same. Thus, the results may 
differ because certain students took both semesters of the course and their experiences with the previous version of the proposed system made them more familiar with it compared with new users.

Item 2 attained a mean value of 2.38, which was 0.50 greater compared with the first investigation, indicating that an increased number of learners did not perceive the system as unnecessarily complex. This result elucidates the change in the standard deviation of Item 2, because learners were likely to rate agree or strongly agree in the first investigation and disagree or strongly disagree in the second investigation. However, this demonstrates that certain learners perceived the system as unnecessarily complex.

Comparing the results from both semesters yields similar item scores, and similar items yielded the highest and lowest scores in both investigations. The SUS scores for Items 4 and 10 were the lowest in both semesters, indicating that although adding detailed instructions and streamlining the process increased the scores, the need for technical support and prior knowledge to use the system remained problematic. The Item 10 score may be difficult to improve because despite improvements, the system requires knowledge of international trade processes. However, the Item 4 score can be improved such that users do not report a need for technical support when using the system.

\section{Open-Ended Question Results from the Second Semester Students}

First, learners perceived that they would become familiar with the international trade process if they frequently used the proposed system. This shows that students familiarized themselves with international trade and improved their relevant skills by frequently using the system.

Second, numerous students who participated in both semesters of the investigation mentioned that "the interface is more user-friendly compared with the former version" and "the function is more user-friendly compared with the former version." Thus, learners perceived the enhanced interface and functions in the revised version of the proposed system.

Third, learners spent less time learning this version compared with the previous version, and the detailed instructions facilitated using the system.

Fourth, in addition to providing positive feedback, learners hoped the system could provide instant notifications. Certain learners also suggested using e-mail as another form of notification. Notifying learners when to perform the next step in the international trade process could raise the level of execution efficiency among students.

Finally, certain learners perceived that the system included sufficient functions and that they merely needed time to become familiar with the system. This shows that certain 
students were satisfied with the system functions. Increasing the functions may cause these students to consider the system as unnecessarily complex.

\section{SUS Results Obtained from Teachers After the Second. Semester}

We designed a colorful annotation module, a learning-file library, and a notification module for teachers, who used the SUS to evaluate these modules. Table 3 shows that the SUS score was 74.45. According to Bangor et al. (2009), this value scores between good and excellent; thus, the proposed system yielded effective system usability to teachers. This section presents a detailed analysis of these results.

Items 1 (3.44 points), 3 (3.44 points), 8 (3.22 points), 7 (3 points), and 9 (3 points) yielded the highest mean scores, demonstrating that the proposed system is easy to use and learn. An optimal user experience allows users to gain enjoyment from using the system.

Items 4 ( 1.59 points) and 10 (1.33 points) yielded the highest standard deviations. Based on Item 4, certain teachers required help learning to use the system, whereas others did not. Similarly, based on Item 10, certain teachers required prior knowledge before using the system, whereas others did not. Although certain teachers indicated their need for technical support, enhanced instructions should be able to help teachers learn how to use the proposed system. 
Table 3

SUS Results (Teacher)

System Usability Scale

1. I think that I would like to use this system frequently.

2. I found the system unnecessarily complex.

3. I thought the system was easy to use

4. I think that I would need the support of a technical person to be able to use this system

5. I found the various functions in this system were well integrated.

6. I thought there was too much inconsistency in this system

7. I would imagine that most people would learn to use this system very quickly.

8. I found the system very cumbersome to use.

9. I felt very confident using the system.

10. I needed to learn a lot of things before I could get going with this system.

SUS score $\underset{\text { mean }}{\text { Contribution }} \mathrm{SD}$

$3.44 \quad 0.73$

$2.89 \quad 0.33$

$3.44 \quad 0.50$

$2.56 \quad 1.59$

$2.78 \quad 0.97$

$2.89 \quad 0.78$

$3.00 \quad 0.00$

$3.22 \quad 0.44$

$3.00 \quad 0.00$

$2.56 \quad 1.33$

74.45

The standard deviations of Items 7 and 9 were both 0.00 , and their mean contribution scores were both 3.00. Thus, although teachers require initial help to use the system, they can effectively use the system after receiving help.

\section{Open-Ended Question Results from Teachers After the Second Semester}

In addition to gathering learner opinions, the teachers completed the open-ended questionnaire to provide their opinions. First, the teachers indicated that the system is easy to use and familiarized themselves with the system following brief instruction. This result is consistent with the SUS scores.

Second, certain teachers indicated that too many colors caused problems in the system, yielding numerous errors and making it difficult for learners to rapidly realize these errors; this decreased the instructional efficiency of the system. The primary difficulty in error correction lies in learner failure to detect errors rather than a lack of knowledge. Adding the error type and a special notation before presenting the error content or showing the error and annotated content may solve this problem. Using this method could also reduce the number of colors required for various errors. Thus, the color selection should be adjusted by considering the relationship between the color and the error. 
Third, certain teachers suggested adjusting the types of errors used in the proposed system based on distinct errors such as the document structure or writing style. However, not all teachers agreed that a specialized error set was required. Offering personalized error types that teachers could customize may solve this problem; however, this could cause confusion regarding error types when students encounter varying error sets. Another possible method could be for teachers to discuss the error sets to be implemented before a semester and before deploying the system.

Fourth, the interface should be improved to enable users to easily notice relevant buttons. Hot keys should also be added for each button.

Fifth, several suggestions were received regarding notifications and the add function. The system should inform teachers when letters awaited error correction to enhance the system efficiency. The system should also provide a learner status, detailing the number of written letters, errors, and login frequency. An active notification mechanism or passive status summary report can also be added to the system, enabling teachers to assess the student status and aid in the learning process. Designing advanced functions could enable the system to automatically detect possible English errors. When correcting letters, teachers can refer to the errors detected by the system to increase the efficiency and quality of error correction. Adding voice-recording functions, allowing teachers to record responses to each error, could also allow learners to rapidly understand their errors.

\section{System Use and Writing Performance Evaluation}

In the summer of 2012, 33 students enrolled in the international trade seminar course. We recorded student login times to analyze the system use habits of students. Figure 4 illustrates the student login time distributions from August 31, 2012 to February 28, 2013. In total, 797 system login times were recorded. The data indicated that 1100 , 1000,2200 , and 2300 hours were the most popular login times, exhibiting 153, 88, 82, and 73 logins, respectively. Most of the login times (635) occurred in the first three months (before November 27, 2012). The reason could be that most students needed to prepare for final exams, or the international trade process was practiced throughout the first three months and students decreased their system use as the course progressed. 


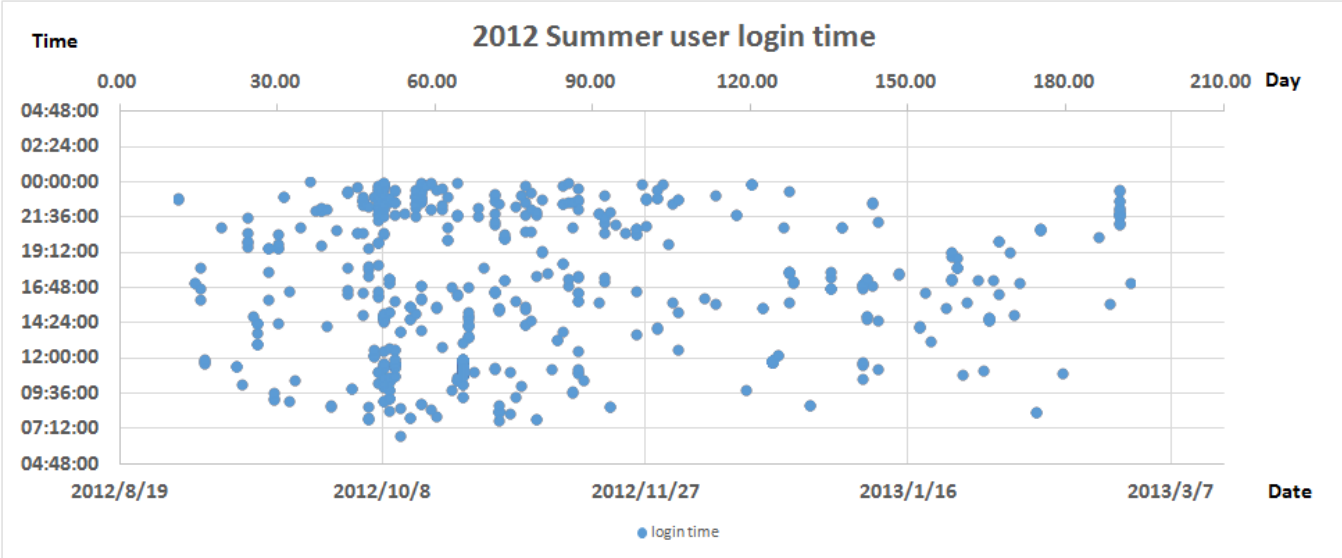

Figure 4. The login time distribution chart for summer 2012.

To assess writing performance levels, we recorded all error numbers in the studentwritten letters (209 letters) and submission dates. Figure 5 shows the error number distribution of each letter. The maximal, minimal, and average numbers of errors per letter were 10,0 , and 0.30 . The linear regression slope was -2.78 , showing that the number of errors in each letter decreased, possibly because of improved student writing skills. In addition to conducting the error number and time analyses, we interviewed the teacher at the end of the semester; he reported that the letter quality improved and the number of errors per letter decreased as the students used the system to practice business-letter writing.

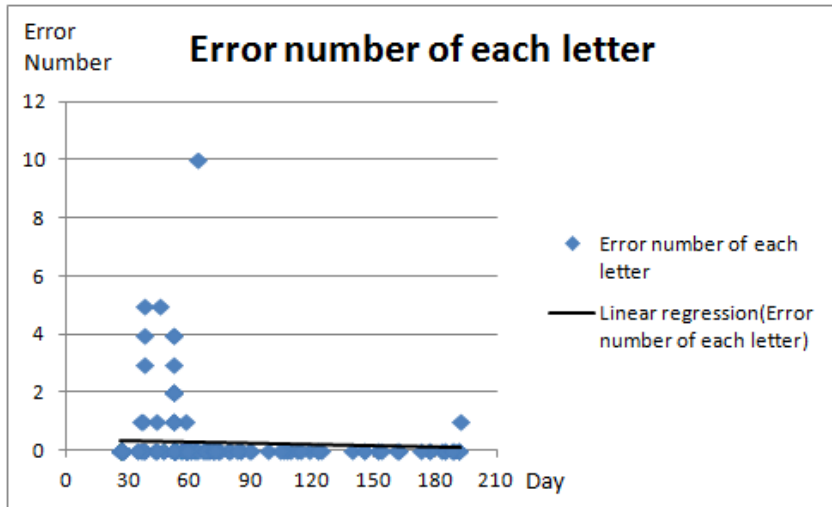

Figure 5. The error number chart for each letter. 


\section{Discussion}

We proposed a simulation-based international trade learning system for both students and teachers, investigated user opinions toward the system, and examined how using the system enhanced the quality of student-generated business letters.

Based on the answers to the open-ended questions, students perceived that the system helped them practice writing English business letters and conducting international trade processes. They also perceived that frequently using the system familiarized them with international trade processes. Thus, the students applied the knowledge they learned from their classes or textbooks in the simulation environment to perform the international process. Simulations allow students to practice and develop skills such as business letter writing. The student SUS results indicated that the system usability increased between the semesters, possibly because we adopted suggestions from the first semester students to enhance the system. The overall teacher SUS grades were higher compared with the student grades, possibly because teachers primarily used the business letter writing functions, whereas students also used the international trade functions, which required simplification. The grades may decrease because of the complexity of the international trade functions. Users also suggested several functions such as e-mail or instant message notifications for both teachers and students. This shows that in addition to system notifications, users wish to receive notifications in various forms. Teachers also suggested several valuable functions such as voice recording, intelligent error detection, and learner status notifications. These functions could be added to the proposed system to relieve the burden on teachers and enhance their understanding of learner status.

The summer 2012 data indicate that student letter-writing quality improved. This could be because the colorful letter-correction and annotation function enhanced student understanding, improving student writing skills after they found and corrected errors.

These findings imply that students can recall and apply their knowledge from class or textbooks in a simulation-based learning environment; practicing in a simulated environment also facilitates developing skills. The proposed system can be used in faceto-face classes or after-school and distance learning. Regarding after-school and distance learning, after a teacher introduces the proposed system to users, it can be used to practice conducting international trade processes in class or after class. If students generate questions, they can query the system and their peers and teacher can also provide feedback to facilitate learning. Future studies could investigate whether and to what extent the proposed system improves international trade skills. International trade companies could also deploy the proposed system to train new employees to observe its training effects. Moreover, after modifying the business letter writing module, it could be used to practice international trade in various languages (e.g., Chinese, J apanese, Russian). Considering other application domains, after replacing the flow process, the proposed system could be applied to teach document flow processes among governmental or industrial institutions. 


\section{Acknowledgement}

This study was supported by the National Science Council of Taiwan under Grant Nos. NSC 102-2511-S-009-006-MY3, NSC 102-2511-S-008-014-MY3, NSC100-2511-S-008017-MY2 and NSC 99-2511-S-009-012-MY3. 


\section{References}

Alessi, S., \& Trollip, S. (2001). Multimedia for learning: Methods and development (3rd ed.). New York: Allyn \& Bacon.

Alexander, B. (2006). Web 2.0: A new wave of innovation for teaching and learning? EDUCAUSE Review, 41(2), 32- 44.

Anderson, T. \& Dron, J . (2011) Three generations of distance education pedagogy. International Review of Research in Open and Distance Learning, 12(3).

Baek, Y. (2009). Digital simulation in teaching and learning. In G. David \&Y. Baek (Eds.), Digital simulations for improving education: Learning through artificial teaching environments (pp. 25-51). IGI Global.

Bangor, A., Kortum, P., \& Miller, J . (2009). Determining what individual SUS scores mean: Adding an adjective rating scale. J ournal of Usability Studies, 4(3), 114123.

Bargeron, D., Gupta, A., Grudin, J ., \& Sanocki, E. (1999). Annotations for streaming video on the web: System design and usage studies. Computer Networks, 31(1116), 1139- 1153.

Barsky, E. (2006). Introducing Web 2.0: RSS trends for health librarians. J ournal of Canadian Health Library Association, 27(1), 7- 8.

Barsky, E., \& Purdon, M. (2006). Introducing Web 2.0: Social networking and social bookmarking for health librarians. J ournal of Canadian Health Library Association, 27(3), 65-67.

Brooke, J . (1986). System usability scale(SUS): A quick-and-dirty method of system evaluation user information. Reading, UK: Digital Equipment Co Ltd.

Chiang, E. P. (2007) Asymmetric information, bargaining, and comparative advantage in trade relationships: An interactive game. Southern Economic J ournal, 74(2), 601-608.

Cho, K. Park, S. R., Nam, D., Ahn, B., \& Lee, J .S.R. (2012). An implementation of computer simulation-based smart learning system for higher education: EDISON. International J ournal of Smart Home, 6(3), 92-98.

Cuene, J . (2005). Web 2.0: Is it a whole new internet? [Presentation slides]. Retrieved 2 J uly, 2013, from http:// cuene.typepad.com/MiMA.1.ppt

Curran, K. (2002). A Web-based collaboration teaching environment. IEEE Multimedia, 9(3), 72- 76. 
Dagneaux, E., Denness, S., \&Granger, S. (1998). Computer-aided error analysis. System, 26(2), 163- 174.

Davis, J ., \& Huttenlocher, D. (1995). Shared annotation for cooperative learning. In Proceedings of CSCL'95, 84- 88.

den Exter, K., Rowe S., Boyd W., \& Lloyd D. (2012) Using Web 2.0 technologies for collaborative learning in distance education-Case studies from an Australian university. Future Internet, 4(1), 216-237.

DiNucci, D. (1999). Fragmented future. Print, 53(4), 32-35.

Downes, S. (2005). E-learning 2.0. eLearn Magazine. Retrieved from http:// elearnmag.acm.org/ featured.cfm?aid=1104968

Dutton, J ., Dutton, M., \& Perry, J . (2002). How do online students differ from lecture students? J ournal of Asynchronous Learning Networks, 6(1), 1- 20.

Ebner, M. (2007). E-Learning 2.0 = e-Learning 1.0 + Web 2.0? In The Second International Conference on Availability, Reliability and Security (ARES'07), 1235- 1239.

Fahy, P.J . (2003). Indicators of support in online interaction. International Review of Research in Open and Distance Learning, 4(1).

Glover, I., Xu Z., \& Hardaker, G. (2007). Online annotation - Research and practices. Computers and Education, 49(4), 1308- 1320.

Holzinger, A. (1997). Computer aided mathematics instruction with Mathematica 3.0. Mathematica in Education and Research, 6(4), 37- 40.

Houston, R. G. \& Hoyt, G. M. (2001). International trade and money: A simple classroom demonstration. Classroom Experinomics, 10.

Hyland, K., \&Hyland, F. (2006). Feedback in second language writing: Contexts and issues. Cambridge: Cambridge University Press.

Kamel Boulos, M. N., \&Wheeler, S. (2007). The emerging Web 2.0 social software: An enabling suite of sociable technologies in health and healthcare education. Health Information and Libraries J ournal, 24(1), 2- 23.

Koory, M. A. (2003). Differences in learning outcomes for the online and F2F versions of "An introduction to Shakespeare". J ournal of Asynchronous Learning Networks, 7(2), 18- 35.

Kubota, M. (2001). Error correction strategies used by learners of J apanese when revising a writing task. System, 29(4), 467- 480. 
Levy, Y. (2007). Comparing dropouts and persistence in e-learning courses. Computers \&Education, 48(2), 185- 204.

Magee, M. (2006). State of the field review: Simulation in education. Retrieved from http:// www.cclcca.ca/pdfs/StateOfField/ SFRSimulationinEducationJ ul06REV.pdf

Miller, S. K. (2001). A review of research on distance education in computers and composition. Computers and Composition, 18(4), 423-430.

Ngai, E. W. T., Poon, J . K. L., \&Chan, Y. H. C. (2007). Empirical examination of the adoption of WebCT using TAM. Computers \& Education, 48(2), 250- 267.

O'Reilly, T. (2007). What is Web 2.0: Design patterns and business models for the next generation of software. Communications \& Strategies, 65, 17- 37.

Ovsiannikov, I. A., Arbib, M. A., \& Mcneill, T. H. (1999). Annotation technology. International J ournal of Human-Computer Studies, 50(4), 329- 362.

Peterson, P. W. (2001). The debate about online learning: Key issues for writing teachers. Computers and Composition, 18(4), 359- 370.

Potter, J . (1992). Common business English errors of Chinese students. Hong Kong: Addison Wesley Longman Asia ELT.

Robinson B., \& Schaible R. M. (1995). Collaborative teaching: Reaping the benefits. College Teaching, 43(2), 57-59.

Sawhney, A., \& Mund, A. (1998). Simulation based construction management learning systems. In Proceedings of the WinterSimulation Conference, 1319- 1324.

Shea, P. J ., Pickett, A. M., \& Peltz, W. E. (2003). A follow-up investigation of "teaching presence" in the SUNY learning network. J ournal of Asynchronous Learning Networks, 7(2), 61- 80.

Smith, D. (2012). Considerations for optimizing online courses with Web 2.0 tools. In Proceedings of World Conference on Educational Multimedia, Hypermedia and Telecommunications 2012, 2913-2917.

Swaak, J ., \& de J ong, T. (2001). Learner vs. system control in using online support for simulation-based discovery learning. Learning Environments Research, 4(3), 217- 241 .

Usluel, Y. K., \& Mazman, S. G. (2009) Adoption of Web 2.0 tools in distance education. Procedia - Social and Behavioral Sciences, 1(1), 818-823. 
Weiss, R. E., Knowlton, D.S., \& Morrison, G. R. (2002). Principles for using animation in computer-based instruction: theoretical heuristics for effective design. Computers in Human Behavior, 18(4), 465- 477.

Wible, D., Kuo, C. H., Chien, F. Y., Liu, A., \& Tsao, N. L. (2001). A Web-based EFL writing environment: Integrating information for learners, teachers, and researchers. Computers and Education, 37(3-4), 297- 315.

Wolfe, J . (2002). Annotation technologies: A software and research review. Computers and Composition, 19(4), 471- 497.

Yang, S. J . H. (2006). Context aware ubiquitous learning environments for peer-to-peer collaborative learning. Educational Technology and Society, 9(1), 188-201.

Yeh, S. W., Lo, J . J., \&Huang, J . J . (2006). The development of an online annotation system for EFL writing with error feedback and error analysis. In Proceedings of ED-Media 2006: World Conference on Educational Multimedia, Hypermedia \& Telecommunications, 2480- 2485.

\section{Athabasca University $\mathbf{a}$}

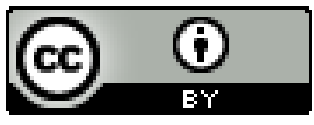

